\title{
Adhesion of filamentous fungi isolated from drinking water under different process conditions
}

\author{
Susana Fernandes ${ }^{\text {a }}$, Lúcia Chaves Simões ${ }^{\text {a, b }}$, Nelson Lima ${ }^{\text {b }}$, Manuel Simões ${ }^{\text {a, * }}$ \\ a LEPABE, Faculty of Engineering, Department of Chemical Engineering, University of Porto, Porto, Portugal \\ ${ }^{\mathrm{b}}$ CEB, Centre of Biological Engineering, University of Minho, Braga, Portugal
}

\section{A R T I C L E I N F O}

\section{Article history:}

Received 4 January 2019

Received in revised form

29 July 2019

Accepted 3 August 2019

Available online 5 August 2019

\section{Keywords:}

Abiotic factors

Adhesion

Biofilm

Drinking water

Filamentous fungi

\begin{abstract}
A B S T R A C T
Filamentous fungi (ff) are consistently recognized as drinking water (DW) inhabitants, typically harboured in biofilms. Their sessile behaviour is still poorly understood. This study aimed the evaluation of the influence of several abiotic factors (substratum, hydrodynamic conditions and nutrient availability) on biofilm formation by Penicillium brevicompactum and P. expansum isolated from DW. Fungal adhesion was quantified on high density polyethylene (HDPE) and polyvinyl chloride (PVC) surfaces using synthetic tap water (STW) and R2A broth, under stagnant or agitated (25 and $150 \mathrm{rpm}$ ) conditions. Fungal spore numbers were assessed after staining with Calcofluor White MR2 and epifluorescence microscopy. The surface charge and physicochemical properties of spores were characterized for a mechanistic understanding on the adhesion process. The adhesion kinetics of spores was represented accurately by the Logistic model, in which adhesion increased with time until a maximum level attained before spore germination ( $8 \mathrm{~h}$ after incubation). In general, $P$. brevicompactum demonstrated to adhere in a higher extent than $P$. expansum $\left(12 \times 10^{4}\right.$ spores $/ \mathrm{cm}^{2}$ vs $1.7 \times 10^{4}$ spores $\left./ \mathrm{cm}^{2}\right)$. Moreover, fungal adhesion was potentiated under stagnation and using R2A broth. HDPE and PVC allowed spore adhesion at similar extents. Adhesion predictions based on the extended Derjaguin, Landau, Verwey and Overbeek (XDLVO) theory corroborated the experimental results, highlighting the role of physicochemical surface properties on the adhesion of spores. These results allowed to refine a model for ff biofilm formation. The overall results help to understand key aspects determining the presence of $P$. brevicompactum and $P$. expansum biofilms in DW, where stagnant conditions and the presence of nutrients should be avoided to prevent ff biofilm formation.
\end{abstract}

(c) 2019 Elsevier Ltd. All rights reserved.

\section{Introduction}

Drinking water (DW) is a basic need for human survival and societal development. DW should be chemically and microbiologically safe, adequate in quantity and acceptable in terms of taste, odour and appearance (Simões and Simões, 2013). The provision of safe DW is still a challenge for DW companies. In fact, even after physical treatments and chemical disinfection, microorganisms can enter the DW distribution system (DWDS), survive under such oligotrophic conditions and colonize the pipe walls, forming biofilms (WHO, 2004). The presence of DW biofilms may induce the degradation of organoleptic properties, promote corrosion, blockage of water pipes, potential accumulation and dispersion of

\footnotetext{
* Corresponding author.

E-mail address: mvs@fe.up.pt (M. Simões).
}

pathogens, health complications associated with mycotoxins, and cause disinfectant demand (Paterson et al., 1997; Percival and Walker, 1999; Siqueira et al., 2011).

Fungi appeared about a billion years ago and are an abundant and diverse group of eukaryotic organisms (Viegas et al., 2016). In general, there are three groups of fungi: filamentous fungi (ff) also called moulds, yeasts, and mushrooms (Hageskal et al., 2009). The incidence of outbreaks of fungal infections is increasing with mortality rates often higher than 50\% (Brown et al., 2012). In 2015, 30 cases of pulmonary infections occurred in the Dominican Republic due to exposure to soil contaminated with spores of Histoplasma capsulatum in tunnels used to access a hydroelectric dam (Armstrong et al., 2017). During 2008-2013, 21 cases of Bipolaris surgical site infections in cardiothoracic surgery patients were described in Texas, Arkansas and Florida, in which 16 case-patients died (76\%) (Vallabhaneni et al., 2016). DW-related outbreaks have not been described yet, but the occurrence of ff and their potential 
for waterborne diseases has been reported (Babič et al., 2017; Skaar and Hageskal, 2015). Thus, ff are receiving focus as DW contaminants and their presence in DW is increasingly being recognized as an emerging public health issue (Fisher et al., 2018).

Fungal survival and proliferation in DW are thought to be related to their ability to form biofilms (Simões et al., 2015). However, information on the sessile behaviour of ff is still scarce. Harding et al. (2009) proposed a pioneer model for ff biofilm formation based on models for bacteria and yeast - comprising different stages: propagule adsorption, active attachment, microcolony formation I, microcolony formation II (or initial maturation), maturation (or reproductive development), and dispersal/planktonic phase. The current state of the art proposes that the setup for ff biofilm starts with spore adhesion (Doggett, 2000; Simões et al., 2015), followed by their germination, which will only begin under suitable environmental conditions (Bosh et al., 1995). Afterwards, hyphal differentiation and substratum invasion produce a complex hyphae net (mycelium), forming a mature biofilm. Similarly to bacterial biofilms, production of polymeric extracellular matrix and quorumsensing substances exist in ff biofilms (Blankenship and Mitchell, 2006). Finally, ff detachment occurs through the release of several forms (spores, sporangia, hyphal fragments) in response to specific environmental cues, biological stimuli or stress (Harding et al., 2009). In water systems, hyphal fragments can disperse by water flow, which contribute to establish a new biofilm (Siqueira and Lima, 2013).

The application of general principles of microbial adhesion to the spore adhesion process proposes that spore-surface interaction starts with instantaneous and reversible physicochemical phenomena, resulting from Liftshitz-van der Waals (LW) attraction forces, electrostatic double layer (EL) forces and Lewis acid base (AB) interactions, in addition to Brownian motion, gravitational forces and hydrophobic interactions (Jones, 1994; Pavithra and Doble, 2008). The succeeding step is characterized by irreversible molecular reactions and cell interactions between related entities (spore-spore and spore-substratum) (Simões et al., 2010). Moreover, in natural environments, adhesion may be influenced by abiotic and biotic factors, namely microbial density, metabolic state, physicochemical characteristics, production of extracellular polymeric substances (EPS), substratum properties (chemical composition, surface charge, hydrophobicity, roughness and texture) and by environmental factors (temperature, $\mathrm{pH}$, time of exposure, fluid flow and concentration of disinfectant) (Simões et al., 2010).

The extended Derjaguin, Landau, Verwey and Overbeek (XDLVO) theory has been applied in different fields, including on the understanding and prediction of microbial adhesion (Absolom et al., 1983; Bayoudh et al., 2009; Liu et al., 2007). This approach describes the total adhesion energy between the biological entity $(S)$ and the substratum $(m)$ in water $(w)\left(G_{S w m}\right)$ as a function of the separation distance between the interacting surfaces $(H)$ (Bayoudh et al., 2009):

$G_{S w m}(H)=G_{S w m}^{E L}(H)+G_{S w m}^{L W}(H)+G_{S w m}^{A B}(H)$

From a thermodynamic point of view, adhesion occurs when $G_{S w m}$ is negative, and repulsion occurs when $G_{S w m}$ is positive (Equation (1)). However, this approach has limitations in predicting bacterial adhesion, as it only considers physicochemical forces and disregards biological factors (Katsikogianni and Missirlis, 2004). On the other hand, fungal spores are characterized for their dormant state and an overall homogenous surface structure, with potential colloidal-like behaviour (Amiri et al., 2005; Zhang and Zhang, 2016).

The purpose of the present work was to understand the influence of selected abiotic factors on fungal adhesion by spores of Penicillium brevicompactum and $P$. expansum, two ff isolated from DW (Gonçalves et al., 2006a). Penicillium spp. are the most frequent ff genera found in DW (Gonçalves et al., 2006a; Hageskal et al., 2006; Pereira et al., 2009). Adhesion was assessed by in vitro tests using microtiter plates and by contact angles measurement for further prediction of adhesion by the XDLVO theory. High density polyethylene (HDPE) and polyvinyl chloride (PVC) coupons were selected as substrata typically found in DWDS (Simões, 2013). Distinct agitation speeds $(0,25$ and $150 \mathrm{rpm})$ and nutrient availability (R2A broth and synthetic tap water - STW) were used for evaluation of spore adhesion.

\section{Materials and methods}

\subsection{Fungi and culture conditions}

P. brevicompactum MUM 05.17 and P. expansum MUM 00.02 were selected for this study due their high occurrence in the tap water of the north of Portugal (Gonçalves et al., 2006a). These ff were supplied by the Micoteca da Universidade do Minho fungal culture collection (MUM, Braga, Portugal).

\subsection{Stock solution of fungal spores}

Stock solutions of spores were prepared according to Simões et al. (2015). Spores of $P$. brevicompactum and $P$. expansum were harvested from 7-day old pure cultures in malt extract agar (MEA), at $25^{\circ} \mathrm{C}$ by flooding the surface of the agar plates with $2 \mathrm{~mL}$ of TWS solution $(0.85 \% \mathrm{NaCl}$ plus $0.05 \%$ Tween 80$)$ and rocking gently. The suspension was homogenized by vortexing and used for large-scale production of spores. The final suspension of spores was homogenized and quantified using a Neubauer count chamber. Several aliquots of suspensions of spores with $10 \%$ of glycerol (HiMedia, India) were cryopreserved at $-80^{\circ} \mathrm{C}$. Stock suspensions were resuspended in a volume of R2A broth or STW [media composition previously described by Gomes et al. (2018)] necessary to achieve a density of $10^{5}$ spores/mL for adhesion assays.

\subsection{Surface materials}

HDPE and PVC were used as substratum for adhesion assays as these represent pipe materials currently used in DWDS (Simões, 2013). For assays in 24-wells microtiter plates, coupons $(1 \mathrm{~cm} \times 1 \mathrm{~cm})$ were washed in a commercial detergent and rinsed in sterile distilled water (Simões et al., 2007a). In order to remove any remaining detergent, they were immersed in ethanol at $70 \%(\mathrm{v} /$ v) for $10 \mathrm{~s}$, following by rinse three times with sterile distilled water. After air dry at room temperature, both sides of coupons were exposed to ultraviolet (UV) radiation for $30 \mathrm{~min}$. The coupons were inserted in the bottom of 24-wells microtiter plates (Orange Scientific, USA) and new UV radiation exposure for 30 min was performed.

\subsection{Surface contact angles measurements}

Spore mats were prepared for contact angle measurements as described for bacterial cells by Busscher et al. (1984). Briefly, suspensions of spores ( $10 \mathrm{~mL}$ of $1 \times 10^{5}$ spores/mL in saline solution) were filtered through a $0.45 \mu \mathrm{m}$ membrane (Whatman) in order to achieve an uniform layer of spores. The surface tension of spores and substrata were determined through sessile drop contact angle method. Contact angles were determined as described by Simões et al. (2007a) at room temperature using three different liquids: two polar - water and formamide -, and one apolar - $\alpha$ - 
bromonaphtalene (Sigma, Portugal). Determination of contact angles (in degrees) was performed automatically using a model OCA 15 Plus (DATAPHYSICS, Germany) video based optical contact angle measure instrument, allowing image acquisition and data analysis. Contact angle measurements (at least 25 determinations) were performed at three independent experiments.

\subsection{Zeta potential measurements}

The measurements of the zeta potential $(\xi)$ of fungal spores and substrata were performed using a Zetasier Nano ZS electrophoretic light scattering spectrophotometer (Malvern Instruments, UK). The spores prepared as described for contact angles measurement were washed two times with PBS and resuspended in sterile distilled water to a final density of $10^{7}-10^{8}$ spores $/ \mathrm{mL}$. For substrata, the coupons previously washed were reduced to small size particles (from 10 to $100 \mu \mathrm{m}$ ). The electrophoretic mobilities $\left(\mu_{e}\right)$ were measured at an applied voltage of $150 \mathrm{~V}$ and $22^{\circ} \mathrm{C}$, then were converted to zeta potential values using the Helmoltz Von Smoluchowski relation (Bayoudh et al., 2009). The experiments were performed in triplicate and repeated three times.

\subsection{Surface thermodynamics and hydrophobicity}

The degree of hydrophobicity of spores and substrata were evaluated as described by Simões et al. (2007a). Through the extended Young equation (Equation (2)), the contact angles $(\theta)$ of a liquid $(L)$ on a solid surface $(i)$ are related with the total surface tension $\left(\gamma_{i}, \mathrm{~mJ} / \mathrm{m}^{2}\right)$, which can be separated into two compounds: Liftshitz-van der Waals $\left(\gamma_{i}^{L W}\right)$ and Lewis acid-base $\left(\gamma_{i}^{A B}\right)$, where $\gamma^{+}$ and $\gamma^{-}$are the electron-acceptor and electron-donor parameters, respectively.

$$
(1+\cos \theta) \gamma_{L}=2\left(\sqrt{\gamma_{i}^{L W} \gamma_{L}^{L W}}+\sqrt{\gamma_{L}^{+} \gamma_{1}^{-}}+\sqrt{\gamma_{i}^{-} \times \gamma_{L}^{+}}\right)
$$

where, $\gamma_{i}=\gamma_{i}^{L W}+\gamma_{i}^{A B}$ with $\gamma_{i}^{A B}=2 \sqrt{\gamma_{i}{ }^{+} \gamma_{i}{ }^{-}}$

The degree of hydrophobicity is expressed as the free energy of interaction between two identical entities $(i)$, when immersed in water $(w)-\Delta G_{i w i}$ (Equation (3)), as the sum of LW and AB interaction free energies. If the interaction between two entities is stronger than their interaction with water $\left(\Delta G_{i w i}<0 \mathrm{~mJ} / \mathrm{m}^{2}\right)$, the material is considered hydrophobic and attraction occurs. On the other hand, if $\Delta G_{i w i}>0 \mathrm{~mJ} / \mathrm{m}^{2}$, the material is hydrophilic, and repulsion occurs. This is calculated for ff spores $\left(\Delta G_{S w S}\right)$ and surface materials $\left(\Delta G_{m w m}\right)$.

$$
\begin{aligned}
& \Delta G_{i w i}=\Delta G_{i w i}^{L W}+\Delta G_{i w i}^{A B}=-2 \gamma_{i w}^{L W}-2 \gamma_{i w}^{A B} \\
& \text { With, }, \gamma_{i j}^{L W}=\left(\sqrt{\gamma_{i}^{L W}}-\sqrt{\gamma_{j}^{L W}}\right)^{2} \text { and } \gamma_{i j}^{A B}=2\left(\sqrt{\gamma_{i}^{+} \gamma_{i}^{-}}+\right. \\
& \left.\sqrt{\gamma_{j}^{+} \gamma_{j}^{-}}-\sqrt{\gamma_{i}^{+} \gamma_{j}^{-}}-\sqrt{\gamma_{i}^{-} \gamma_{j}^{+}}\right) .
\end{aligned}
$$

\subsection{Free energy of adhesion}

The free energy of adhesion between fungal spores $(S)$ and substratum $(m)$ immersed or dissolved in water $(w)-\Delta G_{S w m}$ can be expressed through Equation (4) as the sum of EL, LW and $A B$ free energies of adhesion per unit area (Bayoudh et al., 2009). Thermodynamically, if $\Delta G_{S w m}<0 \mathrm{~mJ} / \mathrm{m}^{2}$, adhesion is favourable; and if $\Delta G_{S w m}>0 \mathrm{~mJ} / \mathrm{m}^{2}$, adhesion is not expected to occur.

$$
\begin{aligned}
& \Delta G_{S w m}=\Delta G_{S w m}^{E L}+\Delta G_{S w m}^{L W}+\Delta G_{S w m}^{A B} \\
& \quad \text { With } \Delta G_{S w m}^{E L}=\frac{\varepsilon_{0} \varepsilon_{r} K}{2}\left(\psi_{S}^{2}+\psi_{m}^{2}\right)\left[1-\operatorname{coth}\left(\kappa l_{0}\right)+\frac{2 \psi_{s} \psi_{m}}{\psi_{S}^{2}+\psi_{m}^{2}} \operatorname{csch}\left(\kappa l_{0}\right)\right] \\
& 10^{-3},
\end{aligned}
$$

$$
\begin{aligned}
& \Delta G_{S w m}^{L W}=-2\left(\sqrt{\gamma_{m}^{L W}}-\sqrt{\gamma_{w}^{L W}}\right)\left(\sqrt{\gamma_{S}^{L W}}-\sqrt{\gamma_{w}^{L W}}\right) \\
& \Delta G_{S w m}^{A B}=2\left[\sqrt{\gamma_{w}^{+}}\left(\sqrt{\gamma_{S}^{-}}+\sqrt{\gamma_{m}^{-}}-\sqrt{\gamma_{w}^{-}}\right)+\sqrt{\gamma_{w}^{-}}\left(\sqrt{\gamma_{S}^{+}}+\sqrt{\gamma_{m}^{+}}\right.\right. \\
&\left.\left.-\sqrt{\gamma_{w}^{+}}\right)-\sqrt{\gamma_{S}^{-} \gamma_{m}^{+}}-\sqrt{\gamma_{S}^{+} \gamma_{m}^{-}}\right]
\end{aligned}
$$

where $\varepsilon_{0}$ is dielectric permittivity in the vacuum $\left(8.854 \times 10^{-12}\right.$ $\left.\mathrm{CV}^{-1} \mathrm{~m}^{-1}\right) ; \varepsilon_{r}$ is the relative permittivity of water $\left(80.1\right.$ at $\left.20^{\circ} \mathrm{C}\right) ; \psi$, stern potential replaced by surface potential $(\mathrm{V}) ; \kappa$ represent the inverse of the Debye length $\left(\mathrm{m}^{-1}\right) ; l_{0}$, the minimum equilibrium distance $\left[1.57 \times 10^{-10} \mathrm{~m}\right.$ (Liu et al., 2008)]. For this study, STW composition was assumed as a background electrolyte of $0.01 \mathrm{mg} / \mathrm{L}$ of $\mathrm{NaCl}$, which corresponds to $\kappa$ of around $1.55 \times 10^{8} \mathrm{~m}^{-1}$.

\subsection{XDLVO-based adhesion energy using Derjaguin approach}

The total interaction energy between a spore $(S)$ and a surface $(m)$ immersed in water $(w)$ along the separation distance $(H, \mathrm{~m})-$ $G_{S w m}\left(\mathrm{kT} \approx 4.11 \times 10^{-18} \mathrm{~mJ}\right)$ was calculated according to the Derjaguin approach described by Hoek and Agarwal (2006):

$$
G_{S w m}(H)=G_{S w m}^{E L}(H)+G_{S w m}^{L W}(H)+G_{S w m}^{A B}(H)
$$
with $G_{S w m}^{E L}(H)=\pi \varepsilon_{r} \varepsilon_{0} r\left[2 \psi_{S} \psi_{m} \ln \left(\frac{1+\exp (-\kappa H)}{1-\exp (-\kappa H)}\right)+\left(\psi_{S}^{2}+\psi_{m}^{2}\right) \ln (1-\right.$
$\exp (-2 \kappa H))] \cdot 10^{-3}$,

$$
G_{S w m}^{L W}(H)=-\frac{A_{H} r}{6 H} \text { with } A_{H}=-12 \pi l_{0}^{2} \Delta G_{S w m}^{L W}
$$

$G_{S w m}^{A B}(H)=2 \pi r \lambda \Delta G_{S w m}^{A B} \exp \left(\frac{l_{0}-H}{\lambda}\right)$

where $A_{H}$ is the un-retarded spore-surface Hamaker constant in water $(\mathrm{mJ}) ; \lambda$ is the characteristic decay length of $A B$ interactions in water $\left(6 \times 10^{-10} \mathrm{~m}\right) ; r$ is the spore radius $(\mathrm{m})$. At distances in which $G_{S w S}<0 \mathrm{kT}$, adhesion may occur; and if $G_{S w S}>0 \mathrm{kT}$, adhesion is not expected to occur.

For predicting autoaggregation of spores, the interaction between spores $\left(G_{S w S}\right)$ was calculated replacing $r$ by $r^{2} / 2 r$ (Equation (5)). At distances under which $G_{S w S}<0 \mathrm{kT}$, autoaggregation is favourable; and if $G_{S w S}>0 \mathrm{kT}$, autoaggregation is not expected to occur.

\subsection{Effect of abiotic factors on fungal adhesion}

Coupons of HDPE and PVC in 24-wells microtiter plates, and suspensions of $P$. brevicompactum and $P$. expansum spores were prepared as described above. Under aseptic conditions, $2 \mathrm{~mL}$ of a suspension of spores in R2A broth or STW was added to each well. To promote ff adhesion, all the plates were incubated for $8 \mathrm{~h}$ [time needed for adhesion to occur and to initiate germling formation (Simões et al., 2015)], aerobically at $25^{\circ} \mathrm{C}$, under static conditions or in an orbital shaker (New Brunswick Scientific, innova ${ }^{\circledR} 44$, USA) at 25 and $150 \mathrm{rpm}$. For each condition, coupons were removed aseptically and washed three times with $2 \mathrm{~mL}$ of sterile saline solution $(0.85 \% \mathrm{NaCl})$, to remove non- and weakly adhered spores. The coupons were air dried to remove water in excess by evaporation. The quantification of adhered spores was performed by epifluorescence microscopy (Nikon eclipse Ci-L, Japan) with Calcofluor White MR2 (CW) (Sigma, Portugal) staining. The negative controls were obtained placing the coupons in R2A broth or STW, without spores. All the experiments were performed in duplicate with three 
independent repeats.

\subsection{Spore counts}

For quantification of $\mathrm{ff}$ adhesion, the coupons were directly stained with $10 \mu \mathrm{L}$ of $25 \mu \mathrm{M} \mathrm{CW}$ and incubated for $15 \mathrm{~min}$, at room temperature and in the dark, according to Gonçalves et al. (2006b). After staining, each coupon was washed two times with sterile distilled water and allowed to air dry. Finally, the samples were observed under a Nikon epifluorescence microscope using UV light and an optical 330-380 nm excitation filter, a LP400 nm emission filter and a $420 \mathrm{~nm}$ barrier filter. The images of adhered spores were acquired with a microscope camera (Nikon DS-Qi2, Japan) using the NIS-Element Microscope Imaging Software. A total of 20 fields were counted for each coupon to assess total spore numbers per $\mathrm{cm}^{2}$.

\subsection{Adhesion kinetics of fungal spores}

The determination of adhesion kinetics of fungal spores was only assessed for $P$. brevicompactum, due to its higher adhesion ability in comparison to $P$. expansum and under the conditions tested. These assays were performed for the several process conditions described previously. Briefly, $2 \mathrm{~mL}$ of suspension of $P$. brevicompactum spores in R2A broth was added to each well with coupons of HDPE or PVC, under aseptic conditions. To promote fungal adhesion, all the plates were incubated aerobically at $25^{\circ} \mathrm{C}$, under static conditions ( $0 \mathrm{rpm})$ and sampled at defined times ( 1,2 , $3,4,6,8$ and $12 \mathrm{~h}$ ). The negative controls were obtained placing the coupons in R2A broth, without spores. All the experiments were performed in duplicate with three independent repeats.

The quantification of ratio of adhered spores over time [ $N=$ $f(t)$ ] was adjusted to the Gompertz model (Equation (6)) and the Logistic model (Equation (7)), which allowed the estimation of relevant parameters on fungal adhesion kinetics (Dantigny et al., 2006):

$N=N_{\max } \exp \left(-\exp \left(\frac{\mu_{m} \exp 1}{N_{\max }}(\lambda-t)+1\right)\right)$

where $N_{\max }$ is the maximum ratio of adhered spores, which corresponds to the asymptotic $N$ value at $t \rightarrow+\infty ; \mu_{m}$ is the maximum adhesion rate as the slope term of the tangent line through the inflection point $\left(\mathrm{h}^{-1}\right) ; \lambda$ corresponds to length of initial latent phase (lag-phase) of adhesion as t-axis intercept of the tangent through the inflection point (h).

$N=\frac{N_{\max }}{1+\exp (k(\tau-t))}$

where $\tau$ is the inflection point, that corresponds to the time of half of $N_{\max }(\mathrm{h}) ; k$ is the maximum adhesion rate related to the slope of the tangent line through the inflection point $\left(\mathrm{h}^{-1}\right)$.

\subsection{Statistical analysis}

The data were analysed using the statistical program SPSS version 24.0. (Statistical Package for the Social Sciences, USA). All data was statistically analysed using one-way ANOVA, based on a confidence level $\geq 95 \%$ ( $P<0.05$ was considered statistically significant). The parameters of Gompertz and Logistic models were estimated with Levenberg-Marquardt method for non-linear regressions.

\section{Results}

\subsection{Physicochemical properties of ff spores and substrata}

Both fungal spores and substrata had negative surface charge in water (Table 1). The surface charge of spores was similar for P. brevicompactum $(-30 \mathrm{mV})$ and $P$. expansum $(-34 \mathrm{mV})$ as well as for the substrata ( -20 and $-18 \mathrm{mV}$ for PVC and HDPE, respectively) $(P>0.05)$.

Spores of $P$. brevicompactum were characterized as hydrophobic $\left(\Delta G_{i w i}<0 \mathrm{~mJ} / \mathrm{m}^{2}\right)$ while those of $P$. expansum as hydrophilic $\left(\Delta G_{i w i}>0 \mathrm{~mJ} / \mathrm{m}^{2}\right)$. The negative $\mathrm{LW}$ component of spores indicated that LW forces were responsible for attraction $\left(\Delta G_{S w S}^{L W}=-\right.$ $6.4 \mathrm{~mJ} / \mathrm{m}^{2}$ ). The $\mathrm{AB}$ component was variable between spores, with values of $21.5 \mathrm{~mJ} / \mathrm{m}^{2}$ ( $P$. expansum) and $-4.5 \mathrm{~mJ} / \mathrm{m}^{2}$ (P. brevicompactum). When dispersed in water, spores of $P$. expansum showed repulsive $\mathrm{AB}$ interactions and smaller LW attraction, due to its strong ability to donate electrons $\left(\gamma^{-}=\right.$ $\left.37.4 \mathrm{~mJ} / \mathrm{m}^{2}\right)$ and no ability to accept electrons $\left(\gamma^{+}=0 \mathrm{~mJ} / \mathrm{m}^{2}\right)$. In contrast, both $\mathrm{AB}$ and LW interactions were attractive for $P$. brevicompactum spores, which had a high electron donating capacity $\left(\gamma^{-}=23.1 \mathrm{~mJ} / \mathrm{m}^{2}\right)$ and very low ability to accept electrons $\left(\gamma^{+}=0.2 \mathrm{~mJ} / \mathrm{m}^{2}\right)$. Additionally, both substrata were characterized as hydrophobic, due to predominant attractive $\mathrm{AB}$ component of $\Delta G_{m w m}$. HDPE had higher hydrophobicity $\left(-82.3 \mathrm{~mJ} / \mathrm{m}^{2}\right)$ than PVC $\left(-41.5 \mathrm{~mJ} / \mathrm{m}^{2}\right)$.

\subsection{Prediction of fungal adhesion}

Fungal adhesion on PVC and HDPE in water was predicted by the XDLVO theory. For that, fungal spores were assumed to be spherical with an average diameter of 3.0 and $3.3 \mu \mathrm{m}$ for P. brevicompactum and $P$. expansum, respectively (Pitt, 2006). The substrata were considered as perfectly smooth surfaces (Hermansson, 1999).

The values of free energies of adhesion per unit area between spores and substrata $\left(\Delta G_{S w m}\right)$ are presented in Table 2 . Both spores had theoretical thermodynamic ability to adhere on PVC and HDPE $\left(\Delta G_{S w m}<0 \mathrm{~mJ} / \mathrm{m}^{2}\right)$. However, $P$. brevicompactum had higher theoretical adhesion potential than $P$. expansum. As both substrata and spores had negatively charged surfaces, EL attraction was negligible. But, LW and AB interactions were attractive at closer distance.

Fig. 1 shows the XDLVO energy of interaction as a function of the separation distance between the spores and the substratum. At large distances spores are attracted to the substratum only by LW interactions while at short distances attractive $A B$ interactions seem to play a role. These results proposed that spores need to overcome the negligible energy barrier (ranging between 1 and $2 \mathrm{kT}$ - resulting from repulsive EL interactions) for irreversible adhesion. At distances in which $G_{S w m}<0 \mathrm{kT}$, fungal adhesion is favoured. Thus, the adhesion of $P$. brevicompactum may occur at distances less than 2.6 and $2.4 \mathrm{~nm}$ on HDPE and PVC, respectively. These distances were lower for $P$. expansum $(2.4$ and $1.8 \mathrm{~nm}$ on HDPE and PVC, respectively).

In addition, the XDLVO theory established that the autoaggregation of spores of $P$. brevicompactum was thermodynamically favoured at distances less than $1 \mathrm{~nm}\left(G_{S w S}<0 \mathrm{kT}\right)$, where attractive LW and $A B$ interactions became of key importance. On the other hand, $P$. expansum had no expected ability to autoaggregate ( $G_{S w S}>0$ for all the distances) (data not shown).

\subsection{Effects of abiotic factors on fungal adhesion}

The number of spores adhered on HDPE and PVC were quantified by direct microscopic observation of coupons (Fig. 2). Spores were uniformly dispersed on the substrata when using STW. In 
Table 1

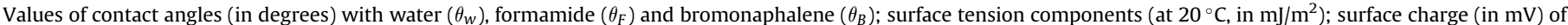

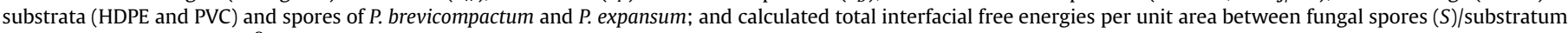
$(\mathrm{m})$ and water $(w)$ (in $\left.\mathrm{mJ} / \mathrm{m}^{2}\right)$. Values are means \pm standard deviations (SDs) of three independent experiments.

\begin{tabular}{|c|c|c|c|c|c|c|c|c|c|c|c|c|}
\hline & \multicolumn{3}{|c|}{ Contact angles $\left(^{\circ}\right)$} & \multicolumn{5}{|c|}{ Surface tension parameters $\left(\mathrm{mJ} / \mathrm{m}^{2}\right)$} & \multirow[t]{2}{*}{ Surface charge (mV) } & \multicolumn{3}{|c|}{$\begin{array}{l}\text { Interfacial free energy }(\mathrm{mJ} / \\
\left.\mathrm{m}^{2}\right)\end{array}$} \\
\hline & $\theta_{w}$ & $\theta_{F}$ & $\theta_{B}$ & $\gamma$ & $\gamma^{L W}$ & $\gamma^{A B}$ & $\gamma^{+}$ & $\gamma^{-}$ & & $\Delta G_{i w i}$ & $\Delta G_{i w i}^{L W}$ & $\Delta G_{i w i}^{A B}$ \\
\hline HDPE & $95.4 \pm 2.5$ & $71.7 \pm 4.3$ & $36.8 \pm 4.3$ & 36.0 & 36.0 & 0.0 & 0.0 & 1.3 & $-18 \pm 3$ & -82.3 & -3.5 & -78.8 \\
\hline PVC & $76.5 \pm 8.9$ & $59.8 \pm 5.9$ & $35.1 \pm 2.9$ & 37.7 & 36.7 & 1.0 & 0.02 & 9.7 & $-20 \pm 3$ & -41.5 & -3.8 & -37.7 \\
\hline P. brevicompactum & $56.0 \pm 2.9$ & $42.1 \pm 2.3$ & $20.4 \pm 0.9$ & 46.2 & 41.7 & 4.5 & 0.2 & 23.1 & $-30 \pm 3$ & -10.9 & -6.4 & -4.5 \\
\hline P. expansum & $51.3 \pm 1.8$ & $51.0 \pm 2.6$ & $19.9 \pm 0.9$ & 41.8 & 41.8 & 0.0 & 0.0 & 37.4 & $-34 \pm 3$ & 15.1 & -6.4 & 21.5 \\
\hline
\end{tabular}

Table 2

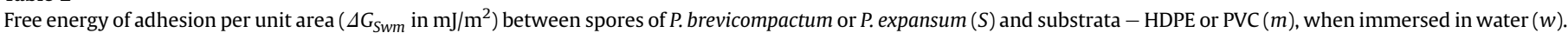
$\Delta G_{S w m}^{E L}$ is the component of EL interaction, $\Delta G_{S w m}^{L W}$ corresponds to LW interaction and $\Delta G_{S w m}^{A B}$ to $A B$ interaction.

\begin{tabular}{|c|c|c|c|c|c|c|c|c|}
\hline & \multicolumn{4}{|l|}{ HDPE } & \multicolumn{4}{|l|}{ PVC } \\
\hline & $\Delta \boldsymbol{G}_{\text {Swm }}$ & $\Delta \boldsymbol{G}_{\text {Swm }}^{E L}$ & $\Delta G_{S w m}^{L W}$ & $\Delta G_{S w m}^{A B}$ & $\Delta \boldsymbol{G}_{\boldsymbol{S w m}}$ & $\Delta \boldsymbol{G}_{\boldsymbol{S w} \boldsymbol{m}}^{\boldsymbol{E L}}$ & $\Delta G_{S w m}^{L W}$ & $\Delta \boldsymbol{G}_{\boldsymbol{S} w \boldsymbol{m}}^{A B}$ \\
\hline $\begin{array}{l}\text { P. brevicompactum } \\
\text { P. expansum }\end{array}$ & $\begin{array}{l}-43.0 \\
-33.6\end{array}$ & $\begin{array}{l}-0.1 \\
-0.3\end{array}$ & $\begin{array}{l}-4.7 \\
-4.7\end{array}$ & $\begin{array}{l}-38.2 \\
-28.6\end{array}$ & $\begin{array}{l}-25.4 \\
-14.6\end{array}$ & $\begin{array}{l}-0.3 \\
-0.5\end{array}$ & $\begin{array}{l}-5.0 \\
-5.0\end{array}$ & $\begin{array}{l}-20.1 \\
-9.1\end{array}$ \\
\hline
\end{tabular}

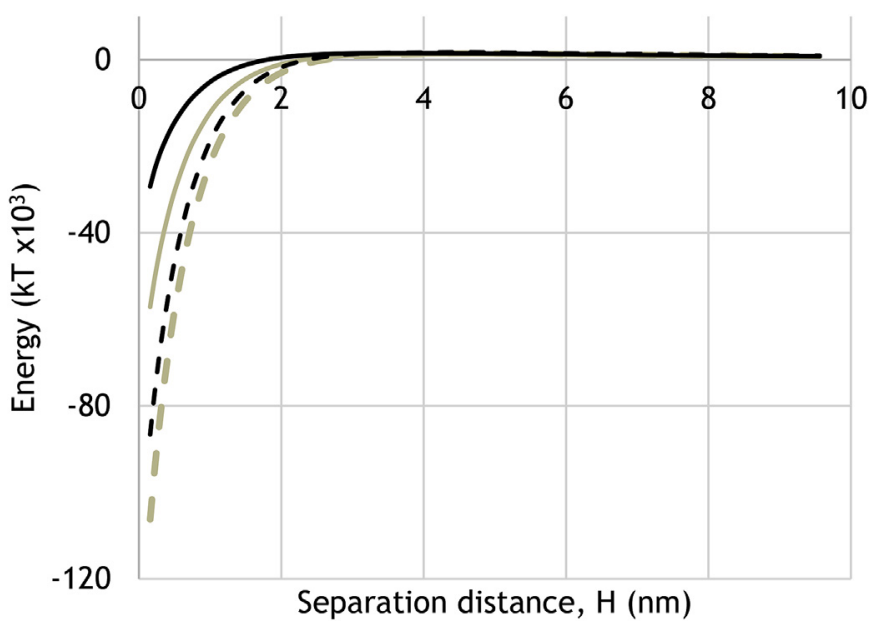

Fig. 1. Interaction energy profiles between spores of $P$. brevicompactum (grey) or P. expansum (black) and HDPE (dashed line) or PVC (continuous line), according to XDLVO theory.

contrast, using R2A broth the spores autoaggregated - a phenomenon noticeable in a higher extent under $150 \mathrm{rpm}$.

Higher counts of adhered spores were found for $P$. brevicompactum than for $P$. expansum $(P<0.05)$ under static conditions, i.e. $12 \times 10^{4}$ and $1.7 \times 10^{4}$ spores $/ \mathrm{cm}^{2}$, respectively (Fig. 2E-F). In general, spore counts were statistically similar for both ff under 25 and $150 \mathrm{rpm}(P>0.05)$, except for HDPE using R2A broth under $25 \mathrm{rpm}$ where the adhesion of $P$. brevicompactum was found to be higher $(P<0.05)$. No effects were observed from the use of HDPE or PVC for both ff adhesion $(P>0.05)$. Moreover, for $P$. expansum no significant differences were found between all conditions studied $(P>0.05)$ - ranging between $0.6 \times 10^{4}$ and $1.7 \times$ $10^{4}$ spores $/ \mathrm{cm}^{2}$. In contrast, the conditions that support higher adhesion of $P$. brevicompactum spores occurred using R2A broth and static conditions $(P<0.05)-11 \times 10^{4}$ and $12 \times 10^{4}$ spores $/ \mathrm{cm}^{2}$ on HDPE and PVC, respectively.

\subsection{Adhesion kinetics of fungal spores}

The adhesion kinetics of fungal spores on HDPE and PVC were studied only for $P$. brevicompactum under static conditions and using R2A broth, which corresponded to the condition promoting higher adhesion. The number of adhered spores per $\mathrm{cm}^{2}$ increased with time before germination that was found $12 \mathrm{~h}$ after incubation (Fig. 3). The maximum adhesion $\left(N_{\max }\right)$, without spore germination, occurred at $8 \mathrm{~h}: N(t \rightarrow 8)=0.56 \pm 0.04$ and $0.62 \pm 0.03$ on HDPE and PVC, respectively. No significant differences were found when comparing adhesion on HDPE and PVC $(P>0.05)$.

The estimated parameters of adhesion kinetics are summarized in Table 3. For adhesion on HDPE, Gompertz and Logistic models estimated equivalent $N_{\max }$, while kinetics on PVC were estimated with more accuracy by the Logistic model. In fact, this model was the most representative of the experimental data - the coefficients of determination $\left(\mathrm{r}^{2}\right)$ were 0.98 (HDPE) and 0.93 (PVC). Adhesion on PVC showed a higher variance on the density of spores around the inflection point. Adhesion on HDPE was faster based on $\mu_{m}$ and $k$ values ( 0.98 and $2.8 \mathrm{~h}^{-1}$ for HDPE $v s 0.10$ and $0.87 \mathrm{~h}^{-1}$ for PVC). However, the lag-phase for adhesion on HDPE was $5.9 \mathrm{~h}$, while for PVC was $2.8 \mathrm{~h}$. According to the Logistic model the half $N_{\max }$ occurred $6.5 \mathrm{~h}$ after incubation, for both substrata.

\section{Discussion}

Filamentous fungi have been recognized as DW contaminants with potential to cause waterborne diseases due to their presence and/or release of mycotoxins (Babič et al., 2017). Recent reports highlighted the emergent resistance of pathogenic ff to antimicrobial agents (Fisher et al., 2018; Siqueira and Lima, 2013). The knowledge on the mechanism of ff biofilm set-up and influence of several abiotic factors on its formation are necessary to develop effective strategies to control their proliferation, ensuring safe and high-quality DW. Microbial adhesion on surfaces is one of the first steps involved in biofilm formation and has been studied extensively over the past decades in many diverse areas, with focus essentially on bacterial adhesion. Very few reports on ff biofilms can be found in the literature (Harding et al., 2009; Siqueira et al., 2011). However, ff are completely adapted for growth on surfaces (Simões et al., 2015). In this study, P. brevicompactum and $P$. expansum were selected to assess fungal adhesion as these species are prevalent in DW (Gonçalves et al., 2006a; Hageskal et al., 2006; Pereira et al., 2009).

Microbial adhesion is influenced by the surface physicochemical 
(A)

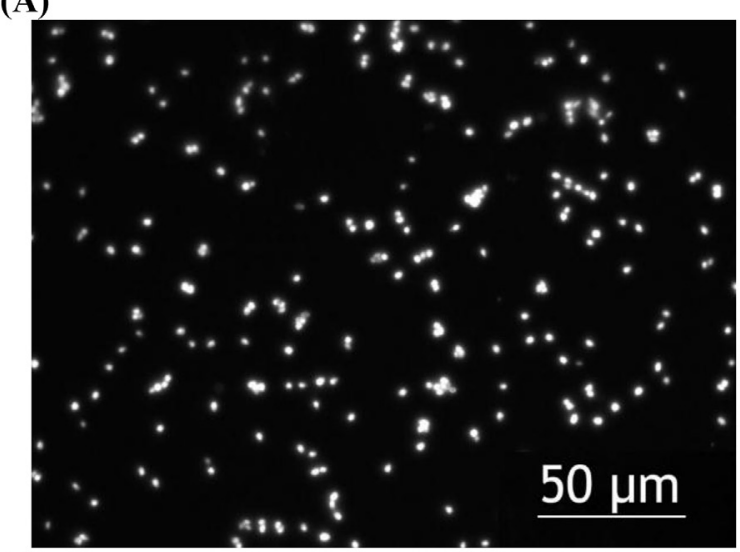

(C)

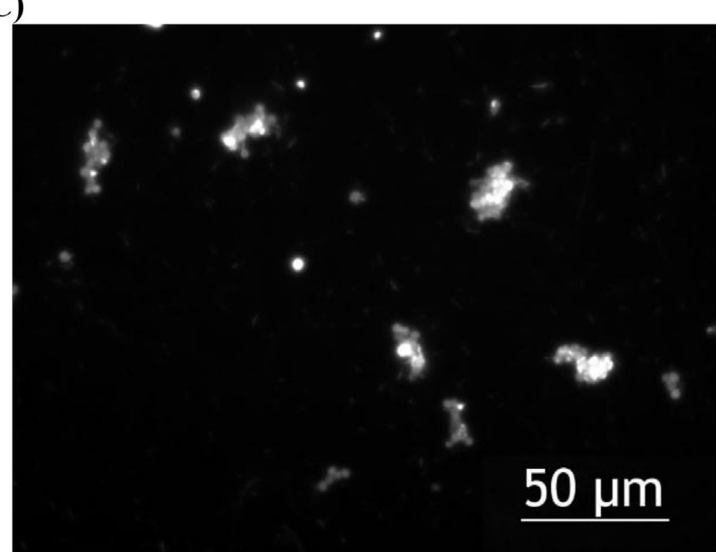

(E)

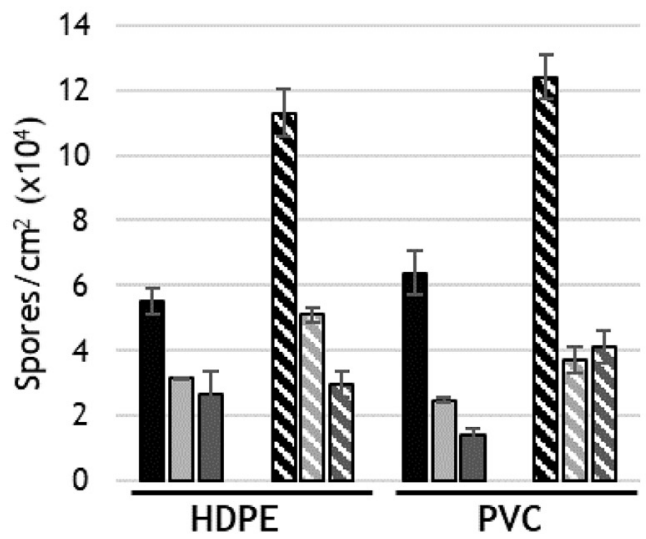

(B)

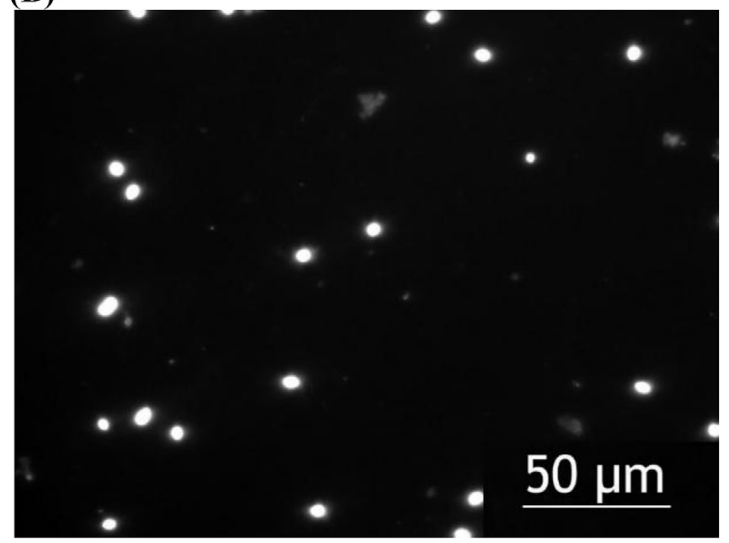

(D)

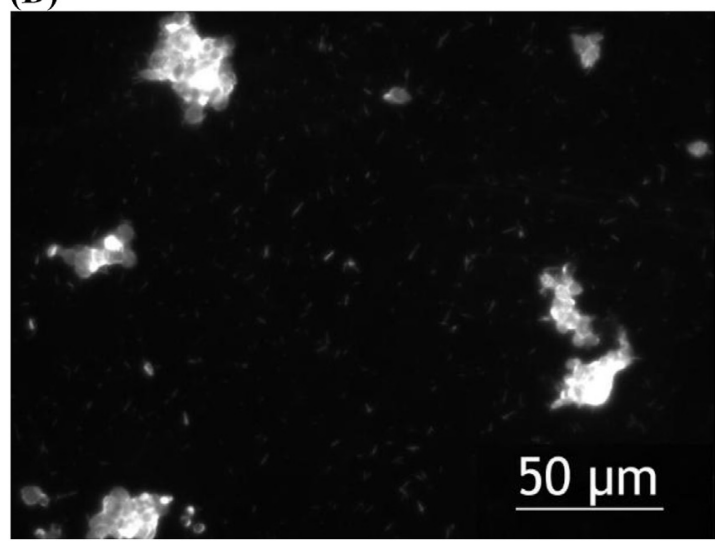

(F)

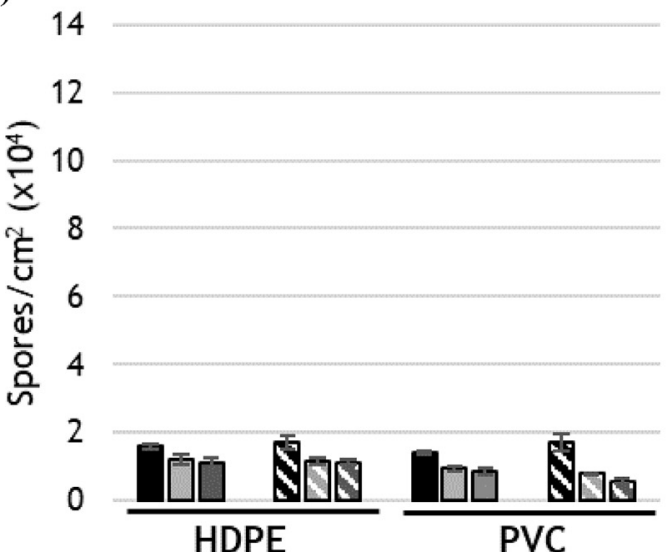

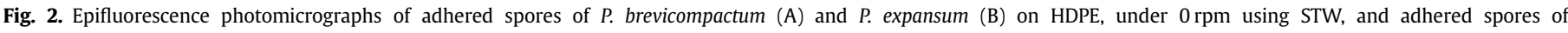

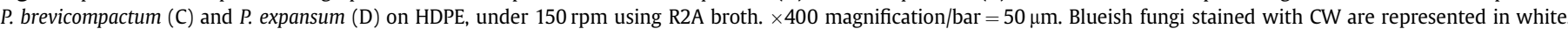

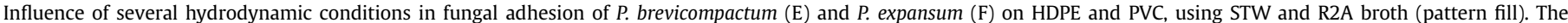
means \pm SDs for at least three replicates are represented. $\square 0 \mathrm{rpm}$; $\square 25 \mathrm{rpm}$; $\square 150 \mathrm{rpm}$.

properties of the microorganisms and the substratum (Donlan and Costerton, 2002). Contact angles measurement by the sessile drop technique is broadly applied to assess the hydrophobicity of bacteria and yeasts (Maataoui et al., 2014; Simões et al. 2007a, 2010; van der Mei et al., 1998). Only a small number of studies were performed with fungal spores (Dunlap et al., 2005; El Abed et al., 2010, 2011; Sadiki et al., 2016). This can be explained by the heterogeneous growth of ff (Chau et al., 2009; Smits et al., 2003) characteristics such as dimorphic growth, variety of size and shapes of hyphae and spores, and a complex cell wall difficult the use of methods established for bacterial studies (Doyle and Rosenberg,
1990; Siqueira and Lima, 2012). Nevertheless, considering that adhesion of ff spores initiates biofilm set-up, it becomes relevant to gather information on ff physicochemical characteristics to understand the adhesion process. This study discloses that both spores demonstrated to be predominantly electron donors and only $P$. brevicompactum had the ability to accept electrons. Several authors found that the surface of spores was essentially electron donor and had weakly electron accepting properties (El Abed et al., 2010, 2011; Seale et al., 2008). Also, spores of $P$. expansum were characterized as hydrophilic and $P$. brevicompactum as hydrophobic. The determination of ff spores surface hydrophobicity appears 
(A)

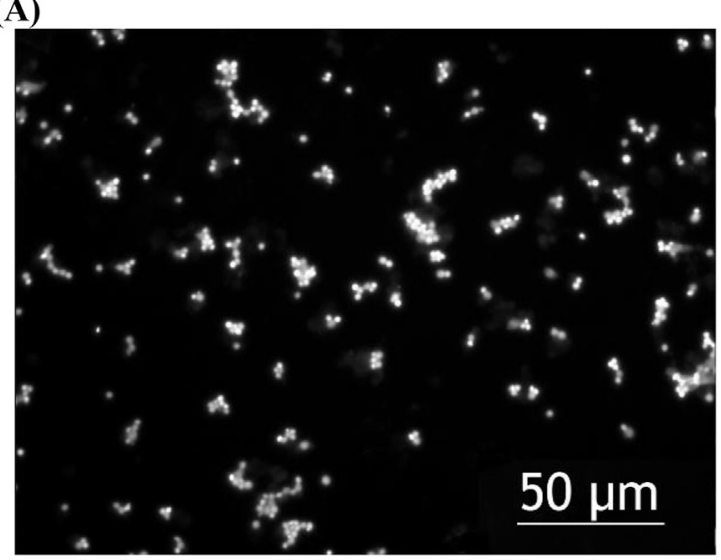

(C)

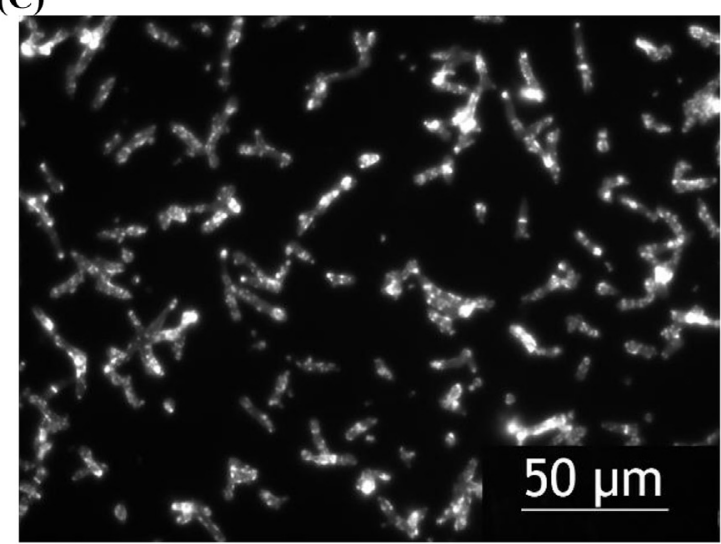

(E)

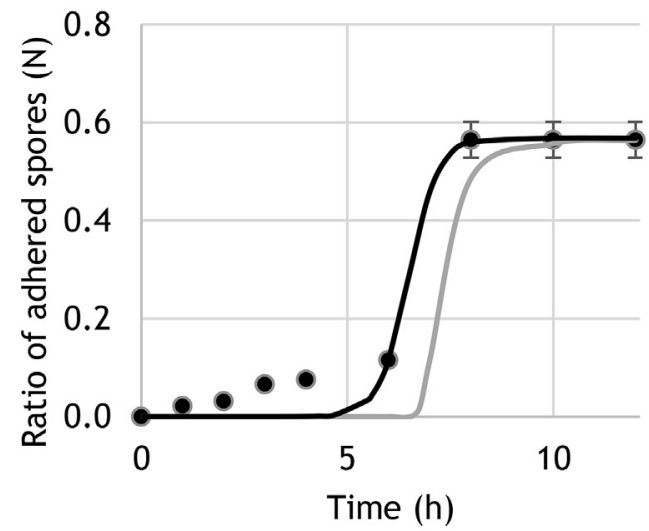

(B)

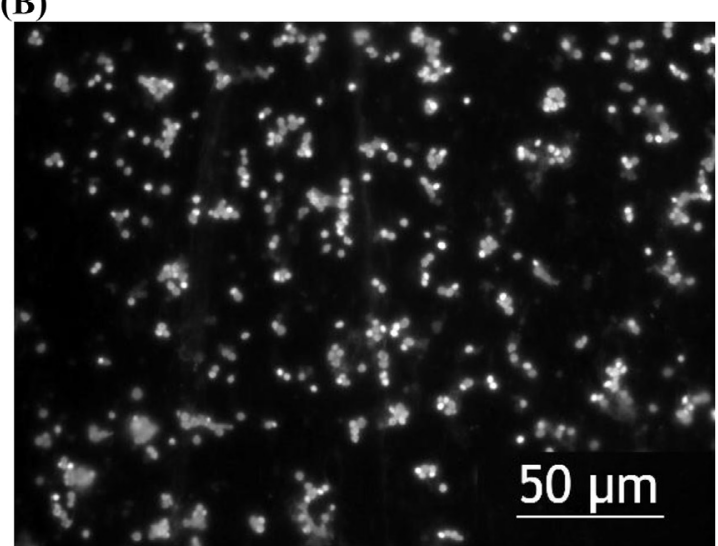

(D)

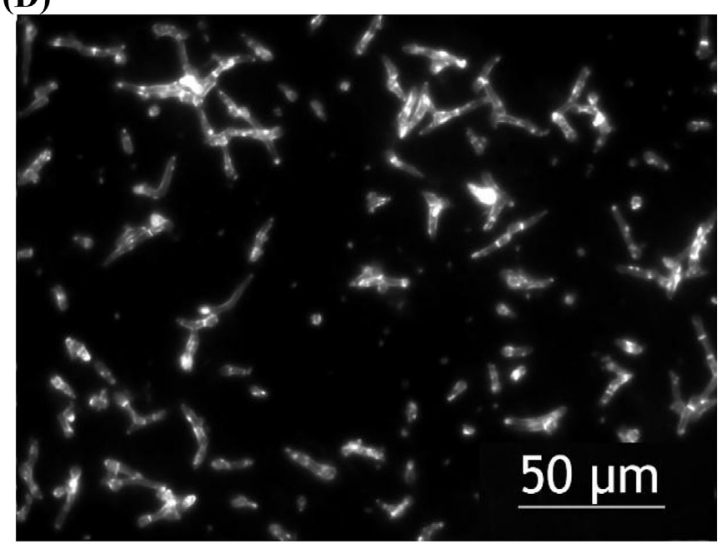

(F)

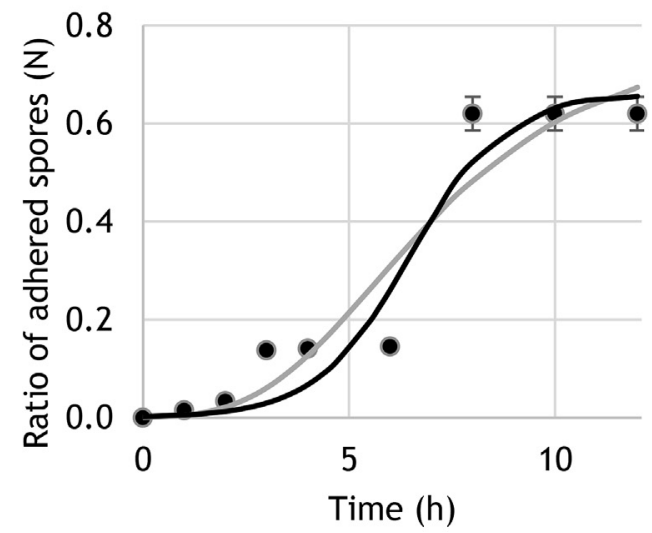

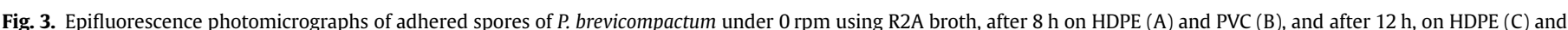

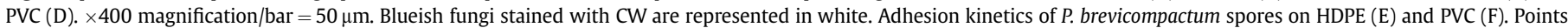

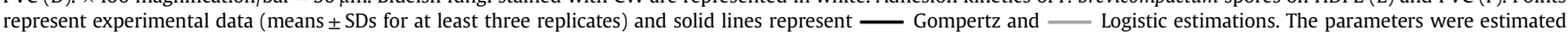
with Levenberg-Marquardt method.

to be imprecise, particularly for $P$. expansum. Previous studies characterized spores of $P$. expansum as hydrophobic (Amiri et al., 2005; Pascual et al., 2000), while more recent studies reported these spores as hydrophilic (El Abed et al., 2010, 2012). It is well established that the hydrophobicity of ff spores is generated by small surface-active proteins, known as hydrophobins (Linder et al.,

Table 3

Parameter values obtained for adhesion of P. brevicompactum on HDPE and PVC with Gompertz and Logistic models. $N_{\max }$ is the maximum ratio of adhered spores; $\mu_{m}$ and $k$ correspond to maximum adhesion rate $\left(\mathrm{h}^{-1}\right) ; \lambda$ is the length of initial latent phase of adhesion; and $\tau$, the time of half of $N_{\max }$

\begin{tabular}{|c|c|c|c|c|c|c|}
\hline & \multicolumn{3}{|l|}{ Gompertz model } & \multicolumn{3}{|l|}{ Logistic model } \\
\hline & $N_{\max }$ & $\mu_{m}\left(\mathrm{~h}^{-1}\right)$ & $\lambda(\mathrm{h})$ & $N_{\max }$ & $\boldsymbol{k}\left(\mathrm{h}^{-1}\right)$ & $\tau(\mathrm{h})$ \\
\hline HDPE & $0.57[0.49 ; 0.64]^{*}$ & $0.98[-188 ; 190]$ & $5.89[-16.1 ; 27.9]$ & $0.57[0.49 ; 0.64]$ & $2.79[-5.20 ; 10.77]$ & $6.49[5.03 ; 7.95]$ \\
\hline PVC & $0.75[0.27 ; 1.24]$ & $0.10[0.02 ; 0.17]$ & $2.78[0.21 ; 5.35]$ & $0.66[-0.48 ; 0.84]$ & $0.87[0.00 ; 1.75]$ & $6.49[4.99 ; 7.99]$ \\
\hline
\end{tabular}

\footnotetext{
* $95 \%$ of confidence intervals in brackets.
} 
2005; Wessels, 1996). They have a role in ff growth as structural components and in their interaction with the environment (Linder et al., 2005). Hydrophobins have been localized on the surface of aerial fungal structures (Wösten, 2001). They mediate the adhesion of fungal structures to hydrophobic surfaces and affect the cell wall composition, promoting surface coating (Van Wetter et al., 2000; Wösten et al., 1994). Thus, during spore germination the swelling implicates the removal of coatings, changing the characteristics of spore wall surface (Zhang and Zhang, 2016). In fact, Amiri et al. (2005) verified that spores of $P$. expansum modified their hydrophobicity with the culture age, from hydrophobic to hydrophilic. This helps to understand the contradicting values of hydrophobicity reported for P. expansum (Amiri et al., 2005; El Abed et al., 2010, 2012; Pascual et al., 2000).

According to the XDLVO theory, both spores had potential to adhere on HDPE and PVC, when immersed in water. The predicted adhesion was higher for the most hydrophobic ff (P. brevicompactum $>$ P. expansum) and substratum (HDPE $>$ PVC). Similar results were obtained by Simões et al. (2007a) for bacterial adhesion. Fungal spores were maintained in suspension due to repulsive $\mathrm{EL}$ interactions with the substratum and due to their negative surface charge caused by the carboxyl and phenol groups (Zhang and Zhang, 2016). At closer distance, short-range interactions ( $\mathrm{LW}$ and $\mathrm{AB}$ ) became more predominant, resulting in spore attraction and consequent adhesion. Thus, for ff spore adhesion to occur it is necessary to overcome the energy barrier and establish direct contact (Bayoudh et al., 2009). There are several factors that could bias this theoretical prediction, particularly the biological changes in the adhered spores and the production of EPS (Katsikogianni and Missirlis, 2004).

The direct microscopic observation reveals that both ff were able to autoaggregate, mainly in the presence of nutrients and under agitation. In fact, hydrodynamic stress potentiate the collision rate between spores (Williams and Crane, 1983) while the medium composition can influence EL interactions (Zhang and Zhang, 2016). The XDLVO theory also predicted the autoaggregation potential of spores: hydrophobic spores of $P$. brevicompactum were found as less stable in suspension, resulting in autoaggregation; repulsion can exist between the hydrophilic spores of $P$. expansum. However, the energy barrier of repulsion was apparently overcome and autoaggregation occurred (Bayoudh et al., 2009).

The adhesion potential of ff spores was evaluated in microtiter plates. These are a device with reproducibility and robustness, which allow the simultaneous screening of different parameters through non-invasive methods of microscopy (Gomes et al., 2014). Following a previous study on ff biofilm formation in DW (Simões et al., 2015), the initial spores density in suspension was about $10^{5}$ spores/mL. The contact time applied was $8 \mathrm{~h}$ to achieve more adhesion without germling formation (Simões et al., 2015). Spore germination occurred at $12 \mathrm{~h}$ incubation and the accurate quantification of spores was difficult due to superposition of hyphae. As predicted by the XDLVO theory, spores of $P$. brevicompactum showed higher adhesion potential than $P$. expansum, which highlight that different ff have different abilities for biofilm development (Busscher et al., 1995; Simões et al., 2007b). In terms of the role of surface type in $\mathrm{ff}$ adhesion, no significant effects were observed from the use of HDPE and PVC. In fact, these surfaces have comparable surface properties, porosity and roughness (Niquette et al., 2000). Adhesion was higher under static conditions and more noticeable when using R2A broth. Before microbial adhesion the surface is naturally conditioned by organic and inorganic substances from the surrounding environment (Donlan, 2002). The results propose that $\mathrm{R} 2 \mathrm{~A}$ broth seems to contribute to the formation of a conditioning film in a higher extent than STW, and consequently to higher adhesion of ff spores. In a real DWDS, low hydrodynamic stress and availability of nutrients could support high ff adhesion. Therefore, reservoirs, corners, valves, dead ends, and zones with low DW consumption are potential places for adhesion of ff spores - due to low hydrodynamic conditions and high residence times. Water stagnation, sediment accumulation and damaged pipe sections (where leaking water pipes can allow organic matter into DW) are known to increase nutrient levels in the DW (EPA, 2002). Such conditions may support high adhesion of spores and appropriate conditions for their germination (Siqueira and Lima, 2013).

Adhesion kinetics of ff spores were described by the Gompertz and Logistic models. These models were already applied to describe the germination and growth kinetics of spores (Dantigny et al., 2006, 2007; 2011; Gougouli and Koutsoumanis, 2012; Huang et al., 2010), and microbial inactivation and growth under different conditions (Chatterjee et al., 2015; Gil et al., 2006). The main difference between them is in the symmetry: Logistic model is symmetric around the inflection point while the Gompertz model is asymmetrical (Dantigny et al., 2011). In this study, the Logistic model demonstrated to be more representative of the experimental data obtained. Adhesion followed a normal distribution around the time that half of maximum adhesion occurred (inflection point $-6.5 \mathrm{~h}$ ). The adhesion rate was found to be higher on HDPE than on PVC. Gompertz model showed that the highest adhesion rate on HDPE should be preceded by a latent phase of $5.9 \mathrm{~h}$.

Based on the results obtained in this study and on data from previous reports (Ramage et al., 2011; Simões et al., 2015; Siqueira and Lima, 2013) a model of ff biofilm formation is proposed (Fig. 4). Initial adhesion of ff spores, i.e. initial physical contact between the spores and the substratum can result in reversible adhesion. This is followed by irreversible adhesion with secretion of adhesive substances by germinated spores and active germlings (Harding et al., 2009). This study focused on the initial adhesion of $P$. brevicompactum and $P$. expansum spores, a phenomenon that happened during the first $8 \mathrm{~h}$ of incubation. The extent of adhesion was influenced by the external conditions (favoured under static conditions and in the presence of nutrients) and physicochemical properties of spores and the substratum. After $12 \mathrm{~h}$ of incubation, germlings start to form and to secrete hydrophobins that selfassemble and change the nature of the surface, mediating adhesion and hyphae-substratum interaction (Zampieri et al., 2010). Thereafter, apical hyphal growth invade the medium (in all directions), crossing each other and being enclosed within the EPS matrix. Internal well-structured channels were described, allowing mass transfer of nutrients and metabolites (Ramage et al., 2011). Finally, the stage of maturation proposed by Harding et al. (2009) for DW biofilms should mainly occur in reservoirs due to requirement of a stable air-water interface for aerial growth and posterior spore formation and air dispersion (Viegas et al., 2016). The dispersion, i.e. fragments of mycelium (propagules) in water or spores through the air, represents the last stage of ff biofilm formation. However, dispersal is counterbalanced by active biofilm growth.

\section{Conclusions}

- In general, spore adhesion on HDPE and PVC was higher for $P$. brevicompactum than for $P$. expansum and the process occurred at spore-substratum nano distance (always lower than $2.6 \mathrm{~nm})$.

- The electrostatic repulsion between the negative surface charge of $P$. brevicompactum/P. expansum spores and the substrata was 


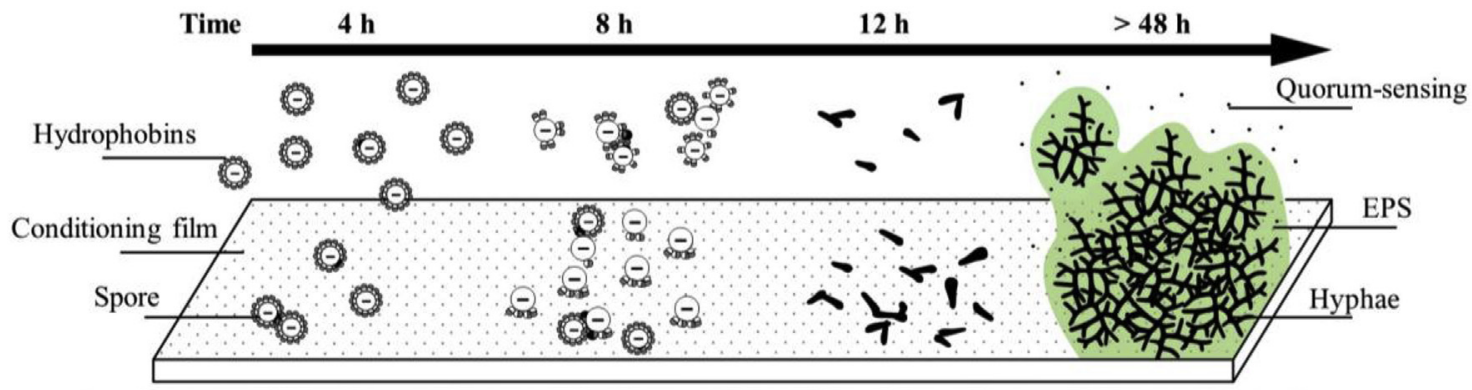

Surface conditioning $\rightarrow$ Spore adhesion $\rightarrow$ Germling formation $\rightarrow$ Mature ff biofilm
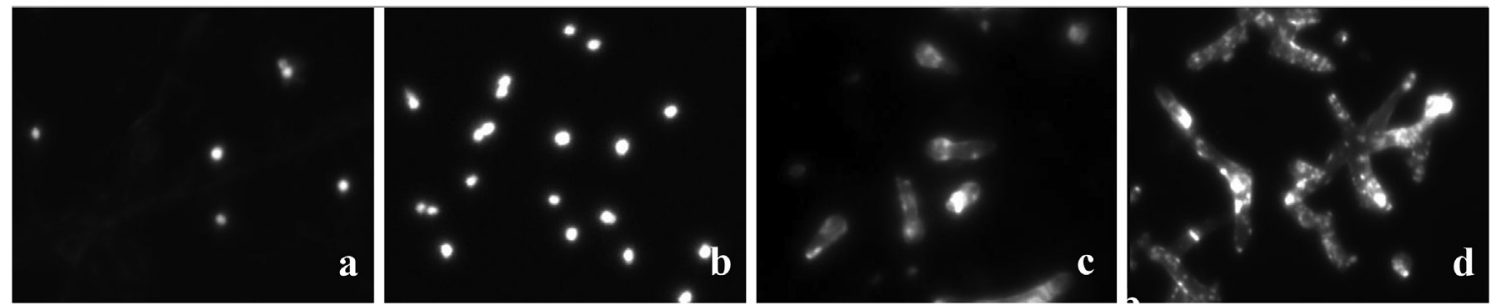

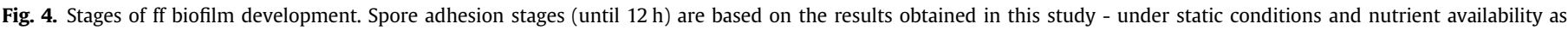

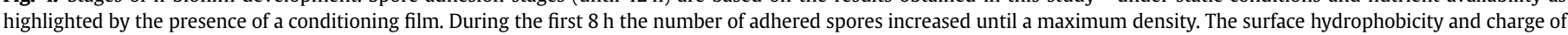

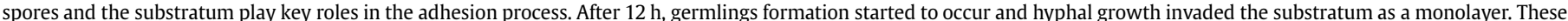

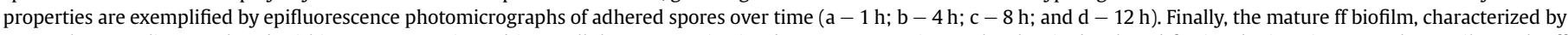

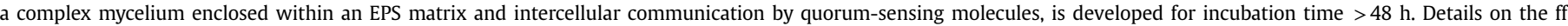
biofilm state are based on previous studies (Ramage et al., 2011; Simões et al., 2015; Siqueira and Lima, 2013).

not impeditive for spore adhesion, regardless the presence/ absence of nutrients and/or hydrodynamic stress.

- The hydrophobicity of the ff spores and the substrata favoured spore adhesion - hydrophilic surfaces should be used to prevent the adhesion of $\mathrm{ff}$ spores.

- Water stagnation and the presence of nutrients should be avoided to prevent the adhesion of ff spores - static conditions and the use of R2A broth potentiated adhesion.

- The XDLVO theory is potentially relevant to study ff adhesion it adequately predicted the adhesion of the selected ff spores on HDPE and PVC, regardless P. brevicompactum spores being hydrophobic while these of $P$. expansum hydrophilic.

- The maximum adhesion of ff spores, without germination, occurred at $8 \mathrm{~h}$ incubation, and spore germination occurred at $12 \mathrm{~h}$ incubation.

- The Logistic equation accurately fitted the experimental data and revealed to be adequate to understand the kinetics of P. brevicompactum spore adhesion.

\section{Conflict of interest disclosure statement}

Authors declare no conflict of interests.

\section{Acknowledgement}

This work was supported by the European Investment Funds by FEDER/COMPETE/POCI - Operational Competitiveness and Internationalization Programme, under Projects: POCI-01-0145-FEDER030219; POCI-01-0247-FEDER-035234; POCI-01-0247-FEDER033298; POCI-01-0145-FEDER-028397; POCI-01-0145-FEDER006958 and National Funds by FCT - Portuguese Foundation for Science and Technology, under the project POCI-01-0145-FEDER006939 - Laboratory for Process Engineering, Environment, Biotechnology and Energy - LEPABE and UID/AGR/04033/2013, and under the scope of the strategic funding of the UID/BIO/04469/2013 unit, COMPETE 2020 (POCI-01-0145-FEDER-006684) and the BioTecNorte operation (NORTE-01-0145-FEDER-000004), funded by the European Regional Development Fund through Norte2020-Programa Operacional Regional do Norte.

\section{References}

Absolom, D.R., Lamberti, F.V., Policova, Z., Zingg, W., Van Oss, C.J., Neumann, A.W., 1983. Surface thermodynamics of bacterial adhesion. Appl. Environ. Microbiol. 46 (1), 90-97.

Amiri, A. Cholodowski, D. Bompeix, G., 2005. Adhesion and germination of waterborne and airborne conidia of Penicillium expansum to apple and inert surfaces. Physiol. Mol. Plant Pathol. 67 (1), 40-48.

Armstrong, P.A., Beard, J.D., Bonilla, L., Arboleda, N., Lindsley, M.D., Chae, S. Castillo, D., Nunez, R., Chiller, T., de Perio, M.A., Pimentel, R., Vallabhaneni, S. 2017. Outbreak of severe histoplasmosis among tunnel workers - Dominican Republic, 2015. Clin. Infect. Dis. 66 (10), 1550-1557.

Babič, M., Gunde-Cimerman, N., Vargha, M., Tischner, Z., Magyar, D., Veríssimo, C., Sabino, R., Viegas, C., Meyer, W., Brandão, J., 2017. Fungal contaminants in drinking water regulation? A tale of ecology, exposure, purification and clinical relevance. Int. J. Environ. Res. Public Health 14 (6), 636-680.

Bayoudh, S., Othmane, A., Mora, L., Ben Ouada, H., 2009. Assessing bacterial adhesion using DLVO and XDLVO theories and the jet impingement technique. Colloids Surf. B Biointerf. 73 (1), 1-9.

Blankenship, J.R., Mitchell, A.P., 2006. How to build a biofilm: a fungal perspective. Curr. Opin. Microbiol. 9 (6), 588-594.

Bosh, A., Maronna, R.A., Yantorno, O.M., 1995. A simple descriptive model of filamentous fungi spore germination. Process Biochem. 30 (7), 599-606.

Brown, G.D., Denning, D.W., Gow, N.A., Levitz, S.M., Netea, M.G., White, T.C., 2012. Hidden killers: human fungal infections. Sci. Transl. Med. 4 (165), 1-9.

Busscher, H.J., Bos, R., van der Mei, H.C., 1995. Initial microbial adhesion is a determinant for the strength of biofilm adhesion. FEMS Microbiol. Lett. 128 (3), 229-234.

Busscher, H.J., Weerkamp, A.H., Van der Mei, H.C., Van Pelt, A.W.J., De Jong, H.P., Arends, J., 1984. Measurement of the surface free energy of bacterial cell surfaces and its relevance for adhesion. Appl. Environ. Microbiol. 48 (5), 980-983.

Chatterjee, T., Chatterjee, B.K., Majumdar, D., Chakrabarti, P., 2015. Antibacterial effect of silver nanoparticles and the modeling of bacterial growth kinetics using a modified Gompertz model. Biochim. Biophys. Acta 1850 (2), 299-306.

Chau, H.W., Si, B.C., Goh, Y.K., Vujanovic, V., 2009. A novel method for identifying hydrophobicity on fungal surfaces. Mycol. Res. 113 (Pt 10), 1046-1052.

Dantigny, P., Bensoussan, M., Vasseur, V., Lebrihi, A., Buchet, C., Ismaili-Alaoui, M., Devlieghere, F., Roussos, S., 2006. Standardisation of methods for assessing mould germination: a workshop report. Int. J. Food Microbiol. 108 (2), 286-291. Dantigny, P., Marin, S., Beyer, M., Magan, N., 2007. Mould germination: data 
treatment and modelling. Int. J. Food Microbiol. 114 (1), 17-24.

Dantigny, P., Nanguy, S.P., Judet-Correia, D., Bensoussan, M., 2011. A new model for germination of fungi. Int. J. Food Microbiol. 146 (2), 176-181.

Doggett, M.S., 2000. Characterization of fungal biofilms within a municipal water distribution system. Appl. Environ. Microbiol. 66 (3), 1249-1251.

Donlan, R.M., 2002. Biofilms: microbial life on surfaces. Emerg. Infect. Dis. 8 (9), $881-890$

Donlan, R.M., Costerton, J.W., 2002. Biofilms: survival mechanisms of clinically relevant microorganisms. Clin. Microbiol. Rev. 15 (2), 167-193.

Doyle, R.J., Rosenberg, M., 1990. Microbial Cell-Surface Hydrophobicity. American Society for Microbiology, Washington, DC.

Dunlap, C.A., Biresaw, G., Jackson, M.A., 2005. Hydrophobic and electrostatic cell surface properties of blastospores of the entomopathogenic fungus Paecilomyces fumosoroseus. Colloids Surfaces B Biointerfaces 46 (4), 261-266.

El Abed, S., Hamadi, F., Latrache, H., Iraqui, H.M., Ibnsouda, K.S., 2010. Adhesion of Aspergillus niger and Penicillium expansum spores on Fez cedar wood substrata. Ann. Microbiol. 60 (3), 377-382.

El Abed, S., Ibnsouda, K.S., Latrache, H., Boutahari, S., 2012. Theoretical effect of cedar wood surface roughness on the adhesion of conidia from Penicillium expansum. Ann. Microbiol. 62 (4), 1361-1366.

El Abed, S., Mostakim, M., Berguadi, F., Latrache, H., Houari, A., Hamadi, F., Ibnsouda, I.K., 2011. Study of microbial adhesion on some wood species: theoretical prediction. Microbiology 80 (1), 43-49.

EPA, 2002. Health Risks from Microbial Growth and Biofilms in Drinking Water Distribution Systems. US Environmental Protection Agency, NW Washington DC.

Fisher, M.C., Hawkins, N.J., Sanglard, D., Gurr, S.J., 2018. Worldwide emergence of resistance to antifungal drugs challenges human health and food security. Science 360 (6390), 739-742.

Gil, M.M., Brandão, T.R.S., Silva, C.L.M., 2006. A modified Gompertz model to predict microbial inactivation under time-varying temperature conditions. J. Food Eng. 76 (1), 89-94.

Gomes, I.B., Simões, L.C., Simões, M., 2018. The effects of emerging environmental contaminants on Stenotrophomonas maltophilia isolated from drinking water in planktonic and sessile states. Sci. Total Environ. 643, 1348-1356.

Gomes, I.B., Simões, M., Simões, L.C., 2014. An overview on the reactors to study drinking water biofilms. Water Res. 62, 63-87.

Gonçalves, A.B., Paterson, R.R.M., Lima, N., 2006a. Survey and significance of filamentous fungi from tap water. Int. J. Hyg Environ. Health 209 (3), 257-264.

Gonçalves, A.B., Santos, I.M., Russell, M., Paterson, M., Lima, N., 2006b. FISH and Calcofluor staining techniques to detect in situ filamentous fungal biofilms in water. Rev. Iberoam. De. Micol. 23 (3), 194-198.

Gougouli, M., Koutsoumanis, K.P., 2012. Modeling germination of fungal spores at constant and fluctuating temperature conditions. Int. J. Food Microbiol. 152 (3), $153-161$.

Hageskal, G., Knutsen, A.K., Gaustad, P., Sybren de Hoog, G., Skaar, I., 2006. Diversity and significance of mold species in Norwegian drinking water. Appl. Environ. Microbiol. 72 (12), 7586-7593.

Hageskal, G., Lima, N., Skaar, I., 2009. The study of fungi in drinking water. Mycol. Res. 113 (2), 165-172.

Harding, M.W., Marques, L.L.R., Howard, R.J., Olson, M.E., 2009. Can filamentous fungi form biofilms? Trends Microbiol. 17 (11), 475-480.

Hermansson, M., 1999. The DLVO theory in microbial adhesion. Colloids Surf. B Biointerf. 14 (1-4), 105-119.

Hoek, E.M., Agarwal, G.K., 2006. Extended DLVO interactions between spherical particles and rough surfaces. J. Colloid Interface Sci. 298 (1), 50-58.

Huang, Y., Begum, M., Chapman, B., Hocking, A.D., 2010. Effect of reduced water activity and reduced matric potential on the germination of xerophilic and nonxerophilic fungi. Int. J. Food Microbiol. 140 (1), 1-5.

Jones, E.B.G., 1994. Fungal adhesion. Mycol. Res. 98 (9), 961-981.

Katsikogianni, M., Missirlis, Y.F., 2004. Concise review of mechanisms of bacterial adhesion to biomaterials and of techniques used in estimating bacteriamaterial interactions. Eur. Cells Mater. 8, 37-57.

Linder, M.B., Szilvay, G.R., Nakari-Setala, T., Penttila, M.E., 2005. Hydrophobins: the protein-amphiphiles of filamentous fungi. FEMS Microbiol. Rev. 29 (5), $877-896$.

Liu, X.M., Sheng, G.P., Wang, J., Yu, H.Q., 2008. Quantifying the surface characteristics and flocculability of Ralstonia eutropha. Appl. Microbiol. Biotechnol. 79 (2), $187-194$.

Liu, X.M., Sheng, G.P., Yu, H.Q., 2007. DLVO approach to the flocculability of a photosynthetic H2-producing bacterium, Rhodopseudomonas acidophila. Environ. Sci. Technol. 41 (13), 4620-4625.

Maataoui, H., Barkai, H., Sadiki, M., Haggoud, A., Koraichi, S.I., Elabed, S., 2014. Physicochemical characterization of actinomycetes isolated from decayed cedar wood: contact angle measurement. J. Adhes. Sci. Technol. 28 (20), 1-8.

Niquette, P., Servais, P., Savoir, R., 2000. Impacts of pipe materials on densities of fixed bacterial biomass in a drinking water distribution system. Water Res. 34 (6), 1952-1956.

Pascual, S., De Cal, A., Magan, N., Melgarejo, P., 2000. Surface hydrophobicity, viability and efficacy in biological control of Penicillium oxalicum spores produced in aerial and submerged culture. J. Appl. Microbiol. 89 (5), 847-853.

Paterson, R.R.M., Kelley, J., Gallagher, M., 1997. Natural occurrence of aflatoxins and Aspergillus flavus (Link) in water. Lett. Appl. Microbiol. 25 (6), 435-436.

Pavithra, D., Doble, M., 2008. Biofilm formation, bacterial adhesion and host response on polymeric implants-issues and prevention. Biomed. Mater. 3 (3), 034003.

Percival, S.L., Walker, J.T., 1999. Potable water and biofilms: a review of the public health implications. Biofouling 14 (2), 99-115.

Pereira, V.J., Basílio, M.C., Fernandes, D., Domingues, M., Paiva, J.M., Benoliel, M.J. Crespo, M.T., San Romão, M.V., 2009. Occurrence of filamentous fungi and yeast in three different drinking water sources. Water Res. 43 (15), 3813-3819.

Pitt, J.I., 2006. In: Blackburn, C.d.W. (Ed.), Food Spoilage Microorganisms. Woodhead Publishing, pp. 437-450.

Ramage, G., Rajendran, R., Gutierrez-Correa, M., Jones, B., Williams, C., 2011. Aspergillus biofilms: clinical and industrial significance. FEMS Microbiol. Lett. 324 (2), 89-97.

Sadiki, M., El Abed, S., Barkai, H., Balouiri, M., El Bergadi, F.Z., Koraichi, S.I., 2016 Plant extracts effect on the cell fungal surface hydrophobicity and acid-base properties. Res. J. Microbiol. 11 (4-5), 139-145.

Seale, R.B., Flint, S.H., McQuillan, A.J., Bremer, P.J., 2008. Recovery of spores from thermophilic dairy Bacilli and effects of their surface characteristics on attachment to different surfaces. Appl. Environ. Microbiol. 74 (3), 731-737.

Simoes, L.C., 2013. In: Simões, M., Mergulhão, F. (Eds.), Biofilms in Drinking Water Nova Science Publishers.

Simões, L.C., Simões, M., 2013. Biofilms in drinking water: problems and solutions. RSC Adv. 3 (8), 2520-2533.

Simões, L.C., Simões, M., Lima, N., 2015. Kinetics of biofilm formation by drinking water isolated Penicillium expansum. Biofouling 31 (4), 349-362.

Simões, L.C., Simões, M., Oliveira, R., Vieira, M.J., 2007a. Potential of the adhesion of bacteria isolated from drinking water to materials. J. Basic Microbiol. 47 (2) $174-183$.

Simões, L.C., Simões, M., Vieira, M.J., 2007b. Biofilm interactions between distinct bacterial genera isolated from drinking water. Appl. Environ. Microbiol. 73 (19) 6192-6200.

Simões, L.C., Simões, M., Vieira, M.J., 2010. Adhesion and biofilm formation on polystyrene by drinking water-isolated bacteria. Antonie Leeuwenhoek 98 (3), 317-329.

Siqueira, V., Lima, N., 2012. Surface hydrophobicity of culture and water biofilm of Penicillium spp. Curr. Microbiol. 64 (2), 93-99.

Siqueira, V., Lima, N., 2013. Biofilm formation by filamentous fungi recovered from a water system. J. Mycol. 1-9, 2013.

Siqueira, V., Oliveira, H.M.B., Santos, C., Paterson, R.R.M., Gusmão, N.B., Lima, N., 2011. Filamentous fungi in drinking water, particularly in relation to biofilm formation. Int. J. Environ. Res. Public Health 8 (2), 456-469.

Skaar, I., Hageskal, G., 2015. In: Paterson, R.R.M., Lima, N. (Eds.), Molecular Biology of Food and Waterborne Mycotoxigenic and Mycotic Fungi. CRC Press, Boca Raton.

Smits, T.H.M., Wick, L.Y., Harms, H., Keel, C., 2003. Characterization of the surface hydrophobicity of filamentous fungi. Environ. Microbiol. 5 (2), 85-91.

Vallabhaneni, S., Purfield, A.E., Benedict, K., Luvsansharav, U., Lockhart, S.R., Pham, C.D., Pascoe, N., Heseltine, G., Chung, W., Hall, E., Brust, K.B., Wheeler, C.F., Halpin, A.L., Park, B.J., 2016. Cardiothoracic surgical site phaeohyphomycosis caused by Bipolaris mould, multiple US states, 2008-2013: a clinical description. Med. Mycol. 54 (3), 318-321.

van der Mei, H.C., Bos, R., Busscher, H.J., 1998. A reference guide to microbial cell surface hydrophobicity based on contact angles. Colloids Surf. B Biointerf. 11 (4) $213-221$.

Van Wetter, M.A., Wösten, H.A.B., Sietsma, J.H., Wessels, J.G., 2000. Hydrophobin gene expression affects hyphal wall composition in Schizophyllum commune. Fungal Genet. Biol. 31 (2), 99-104.

Viegas, C., Pinheiro, A.C., Sabino, R., Viegas, S., Brandão, J., Veríssimo, C., 2016. Environmental Mycology in Public Health - Fungi and Mycotoxins Risk Assessment and Management. Academic Press.

Wessels, J.G.H., 1996. In: Poole, R.K. (Ed.), Advances in Microbial Physiology, pp. $1-45$.

WHO, 2004. Safe Piped Water.

Williams, J.J.E., Crane, R.I., 1983. Particle collision rate in turbulent flow. Int. J. Multiph. Flow 9 (4), 421-435.

Wösten, H.A.B., 2001. Hydrophobins: multipurpose proteins. Annu. Rev. Microbiol. $55,625-646$

Wösten, H.A.B., Schuren, F.H.J., Wessels, J.G.H., 1994. Interfacial self-assembly of a hydrophobin into an amphipathic protein membrane mediates fungal attachment to hydrophobic surfaces. EMBO J. 13 (24), 5848-5954.

Zampieri, F., Wösten, H.A.B., Scholtmeijer, K., 2010. Creating surface properties using a palette of hydrophobins. Materials 3 (9), 4607-4625.

Zhang, J., Zhang, J., 2016. The filamentous fungal pellet and forces driving its formation. Crit. Rev. Biotechnol. 36 (6), 1066-1077. 